\title{
Technological and Sensory Properties of Baby Purees Formulated with Andean Grains and Dried with Different Methods ${ }^{+}$
}

\author{
María Dolores Jiménez, Manuel Oscar Lobo and Norma Cristina Sammán * \\ Faculty of Engineering- CIITED CONICET, National University of Jujuy, San Salvador de Jujuy 4600, \\ Argentina; doloresjimenez4@gmail.com (M.D.J.); mlobo958@gmail.com@gmail.com (M.O.L.) \\ * Correspondence: normasamman@gmail.com \\ † Presented at the 2nd International Conference of IaValSe-Food Network, Lisbon, Portugal, \\ 21-22 October 2019.
}

Published: 26 August 2020

\begin{abstract}
The aim of this work was to compare different cooking-drying methods to obtain dehydrated baby purees. Flours of quinoa and amaranth (native and germinated) were used to formulate them. Dry powders (DPs) were obtained by lyophilization (LD), convection (CD), and extrusion (ED). Proximal composition, particle size and morphology, water absorption capacity, and solubility were evaluated in DPs. Color, texture profile (TP), and sensory characteristics were determined in fresh pure and rehydrated powders (RPs). The LD particles were smaller and homogeneous; CD showed collapsed particles, and ED presented agglomerated particles. Different drying methods influenced the rehydration properties of DPs, as well as the color, TP, and sensory evaluation of RPs. The best method to obtain dehydrated baby purees was extrusion.
\end{abstract}

Keywords: amaranth; Andean potato; dehydrated powder; germination; puree; quinoa

\section{Introduction}

Complementary feeding begins after the first six months of life for babies. The feeding in this stage is fundamental for their physical and mental development. The incorporated foods must have semi-solid consistency and be very digestible [1].

The quinoa and amaranth Andean grains are free of gluten, have proteins of high biological value, and are rich in minerals, vitamins, fiber, and antioxidant compounds. During germination of grains, proteins, lipids, and starches are hydrolyzed, and the content of antioxidant compounds improves. The germinated grains are suitable for the formulation of baby foods due to their greater digestibility with respect to the native grains; however, the modifications that occur during germination influence the thermal, rheological, textural, and sensory characteristics of the final product [2].

The equilibrium humidity of dehydrated foods ensures their microbiological, chemical, and enzymatic stability over a prolonged period. It is important to determine the appropriate drying method for each type of food, because the variables of the process influence the nutritional, technological, and sensory characteristics of the dehydrated and rehydrated food $[3,4]$.

The aim of this work was to formulate a dehydrated puree to reconstitute for babies that is made with quinoa and amaranth flours (germinated and non-germinated). 


\section{Materials and Methods}

\subsection{Raw Material}

Quinoa (Cica), amaranth (Mantegazzianus), and Andean potato (Collareja) were obtained from Centro de Investigación y Desarrollo Tecnológico para la Agricultura Familiar, Hornillos, JujuyArgentina.

\subsubsection{Mashed Potato}

Potatoes were washed, cooked in boiling water, peeled, and mashed.

\subsubsection{Non-Germinated and Germinated Grain Flours}

The grains were washed, and the saponin of quinoa was removed. A part of the washed grains was soaked in tap water $\left(6 \mathrm{~h}\right.$, at room temperature) and sprouted $\left(22-24{ }^{\circ} \mathrm{C}, 80-90 \% \mathrm{RH}\right.$, in darkness) $24 \mathrm{~h}$ quinoa and $48 \mathrm{~h}$ amaranth. Then, they were dried in a forced circulation oven $\left(50^{\circ} \mathrm{C}\right)$ and milled.

\subsection{Fresh Puree and Dry Powders}

\subsubsection{Fresh Puree (FP)}

Mixture of mashed Andean potato $(8.0 \mathrm{~g})$, flours of quinoa $(5.0 \mathrm{~g})$, germinated quinoa $(2.0 \mathrm{~g})$, amaranth $(3.0 \mathrm{~g})$, and germinated amaranth $(1.0 \mathrm{~g})$ with dry milk $(3.0 \mathrm{~g})$, sugar $(3.0 \mathrm{~g})$, and tap water $(81 \mathrm{~mL})$ were cooked $(30 \mathrm{~min})$. Banana essence $(400 \mu \mathrm{L})$ and citric and ascorbic acids $(0.025$ and 0.015 $\mathrm{mL}$, respectively) were added. The cooked puree was packed in glass flasks with screwed metal caps and autoclaved $\left(119^{\circ} \mathrm{C}, 15 \mathrm{~min}\right)$.

\subsubsection{Freeze-Drying (LD)}

The cooked puree was frozen at $-70{ }^{\circ} \mathrm{C}$, and then freeze-dried at $-70{ }^{\circ} \mathrm{C}$ and pressure of 0.15 mbar during $24 \mathrm{~h}$, in Heto FD4 (Heto-Holten, Denmark).

\subsubsection{Drying by Forced Air Circulation (CD)}

It was carried out by using a convective dryer Memmert Radiant Warmer Model A52200-35_Vac 230 (Memmert, Schwabach, Germany). The cooked puree was distributed with a thickness of $1.9 \mathrm{~mm}$ on a tray and dried $\left(40^{\circ} \mathrm{C}, 12 \mathrm{~h}\right)$. An air flow of $55 \mathrm{ft} 3 / \mathrm{h}$ was used.

\subsubsection{Extrusion (ED)}

The mixture of the flours with the other ingredients were extruded, using a twin-screw extruder DT65 (Incalfer, Buenos Aires, Argentina), with a feed rate of $12 \mathrm{~kg} / \mathrm{h}$, water flow of $100 \mathrm{cc} / \mathrm{min}$, and screw speed of $1500 \mathrm{rpm}$ (die diameter $3.0 \mathrm{~mm}$ ). Extrusion was carried out with three temperature sectors $\left(45,175\right.$, and $\left.180{ }^{\circ} \mathrm{C}\right)$.

\subsubsection{Dry Powders (DPs)}

They were obtained from fresh puree by freeze-drying, forced air circulation, and extrusion. The samples were milled in a centrifugal mill CHINCAN model FW 100 (CHINCAN, Hangzhou, China), vacuum-packed in polyethylene bags, and stored at room temperature.

\subsection{Proximal Composition}

It was determined by official techniques AOAC [5] moisture (method 925.10), ash (method 923.03), lipid (Soxhlet method), and total nitrogen (method 920.87). Nitrogen-protein conversion factors 6.25 was used. Carbohydrate was determined by difference. 


\subsection{Particle Morphology}

Particle morphology was studied by scanning electron microscope (SEM), using SEM Zeiss Supra model 55 VP (Zeiss, Oberkochen, Germany). The powders were placed on a specimen holder, with the help of double-sided Scotch Tape and sputter-coated with gold ( $2 \mathrm{~min}, 2 \mathrm{mbar}$ ), and finally each sample was transferred to a microscope, where it was observed $\left(15 \mathrm{kV}, 9.75 \times 10^{-5}\right.$ Torr).

\subsection{Rehydration Properties}

\subsubsection{Solubility and Water Absorption Capacity}

The solubility and water absorption capacity (WAC) were studied according to Wani et al. [6]. DP was weight in a tared centrifuge tube, and water was added. It was mixed and then centrifuged. The supernatant was recovered and dried in a convection oven. The dry solid was weight, and the solubility calculated as $\mathrm{g}$ soluble solids/100 g product. The precipitate was weighed, and WAC was calculated as $\mathrm{g}$ water absorbed/g product.

\subsubsection{Water Adsorption}

It was determined according to Tonon et al. [7]. DP was weight $(2.2 \mathrm{~g})$ in capsules and placed in a chamber $\left(25^{\circ} \mathrm{C}, 76 \% \mathrm{RH}\right.$ achieved with 6 molal $\mathrm{NaCl}$ solution). Water activity and moisture were registered. The experimental data were modeled with the BET equation (Equation (1)):

$$
\text { BET (Brunauer, Emmett, and Teller): } \quad X=\frac{\mathrm{Xm} \text { Caw }}{(1-\mathrm{aw})[1+(\mathrm{C}-1) \mathrm{aw}]}
$$

where $\mathrm{Xm}$ is the moisture of the product corresponding to a monomolecular layer of absorbed water, and $C$ is the energy constant of the product related to the heat released in the process.

\subsection{Physical Characteristics}

\subsubsection{Color}

The color of the rehydration powders (RPs) was evaluated with Color Quest XE colorimeter (Hunter Associates Laboratory, Virginia, USA) and was expressed with the $\mathrm{L}^{*}, \mathrm{a}^{*}$, and $\mathrm{b}^{*}$ parameters.

\subsubsection{Texture Profile Analysis (TPA)}

The TPA of FP and RP was conducted by using a TA-XT Plus Texture Analysis (Stable Micro Systems, Godalming, UK). The factors determined were hardness (H), adhesiveness (A), cohesiveness $(\mathrm{C})$, gumminess $(\mathrm{G})$, and chewiness $(\mathrm{C})$. The purees $(50 \mathrm{~g})$ were subjected to compressive force by probe, up to the distance of $5 \mathrm{~mm}$, with a $1 / 4$ " $\mathrm{P} / 0-25$ stainless-steel cylindrical probe. The conditions set were as follows: two penetration cycles, pre-test speed $0.5 \mathrm{~mm} / \mathrm{s}$; post-test speed $1.0 \mathrm{~mm} / \mathrm{s}$; depth of $16 \mathrm{~mm}$; test time of $3 \mathrm{~s}$; trigger force $5 \mathrm{~g}$.

\subsection{Sensory Evaluation and Acceptability}

The sensory evaluation and acceptability of FP and RP were evaluated with 50 adults. The purees (10 g each) were presented in plastic cups. The acceptability was evaluated according to a hedonic scale of 9 points, with ends (1) "I do not like" and (9) "I like very much". Acceptability was calculated as the average score of the hedonic scale.

The sensory evaluation was studied by CATA (check-all-that-apply) questions. A list of 20 terms was presented to the consumers: pleasant, unpleasant, clear, dark, hard, soft, sandy, creamy, consistence, fluid, and flavor (smooth, intense, sweet, salty, cereal-like, acid, bitter, strange, artificial, rancid, and fruity). Consumers were instructed to tick the terms that most accurately describe the products. Frequency of mention for each term was determined by counting the number of consumers that used that term to describe each sample. 


\subsection{Statistics Analysis}

All analyses were carried out in triplicate. Statistical analysis was done by using one-way analysis of variance (ANOVA). Tukey test was used to assess any differences between group means. Differences were considered significant at $\mathrm{Q}<0.05$. Statistic for Windows version 9.0 (USA) was used.

\section{Results}

\subsection{Proximal Composition}

Table 1 shows the proximal composition of the mixture of ingredients to elaborate the puree and DP obtained by different drying methods. The protein and ash content did not show significant variations after drying; however, lipid content significantly decreased after cooking and dehydration.

Table 1. Proximal composition of fresh puree and dry powders (g/100 g db).

\begin{tabular}{cccccc}
\hline Sample & Moisture & Ash & Protein & Fat & Carbohydrates \\
\hline MP & $9.64 \pm 0.28^{\mathrm{b}}$ & $3.84 \pm 0.20^{\mathrm{a}}$ & $10.71 \pm 0.29^{\mathrm{a}}$ & $6.77 \pm 0.17^{\mathrm{a}}$ & 78.68 \\
LD & $5.89 \pm 0.19^{\mathrm{c}}$ & $3.82 \pm 0.12^{\mathrm{a}}$ & $10.47 \pm 0.36^{\mathrm{a}}$ & $5.42 \pm 0.21^{\mathrm{b}}$ & 80.29 \\
CD & $11.04 \pm 0.65^{\mathrm{a}}$ & $3.59 \pm 0.12^{\mathrm{a}}$ & $10.21 \pm 0.10^{\mathrm{a}}$ & $3.72 \pm 0.16^{\mathrm{c}}$ & 82.47 \\
ED & $8.93 \pm 0.15^{\mathrm{b}}$ & $3.44 \pm 0.09 \mathrm{a}$ & $10.26 \pm 0.35^{\mathrm{a}}$ & $2.66 \pm 0.15^{\mathrm{d}}$ & 83.65 \\
\hline
\end{tabular}

Values are means \pm standard deviations from triplicate analysis. Different superscript letters in the same column indicated significant difference $(p<0.05)$. MP: mixture of ingredients to elaborate the purees; LD: lyophilized; CD: dehydrated by convection; ED: extruded.

\subsection{Particle Morphology}

Figure 1 shows the scanning electron micrographs of the DP. The LD had particles that were more homogeneous and smaller in size, while ED had larger particles with agglomerated appearance. The CD had particles with a collapsed appearance.

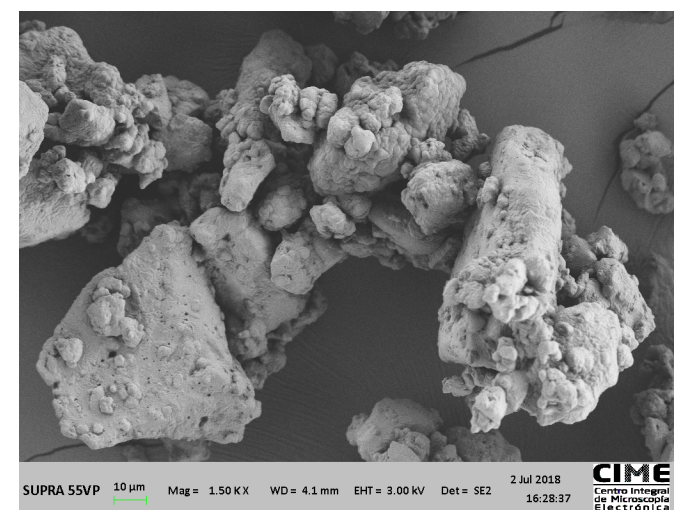

(a)

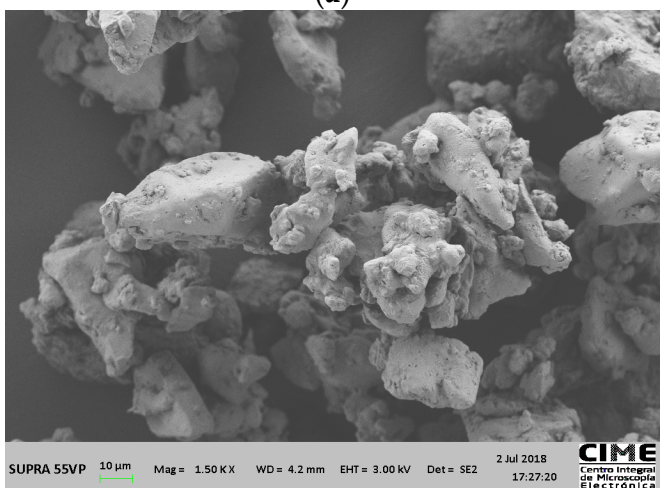

(b) 


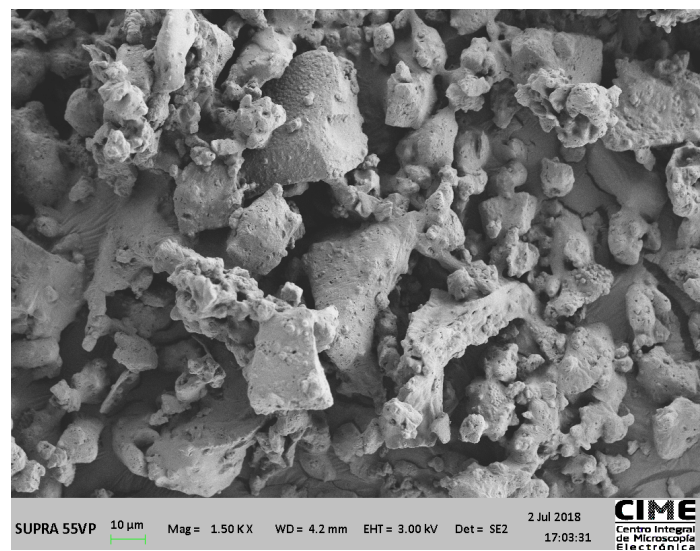

(c)

Figure 1. Scanning electron micrographs of dehydrated powders (1500X): (a) drying by forced circulation, (b) extruded, and (c) lyophilized.

\subsection{Rehydration Properties}

ED was the least soluble, probably due to the agglomeration of its particles [8], but it had the greatest WAC. The LD was the most soluble and had the least WAC (Table 2). The BET model had high fit with the experimental data $\left(R^{2}>0.90\right.$ and \%E <3.00) (Table 2). Xm represents the optimum moisture content in which the dehydrated product will have the maximum shelf life during storage. The ED had the lowest $\mathrm{Xm}$ value.

Table 2. Rehydration properties of the powders obtained by different drying.

\begin{tabular}{ccccc}
\hline & LD & CD & ED \\
\hline Solubility (g/100 g) & $52.59 \pm 0.33^{\text {a }}$ & $48.53 \pm 0.29 \mathrm{~b}$ & $27.90 \pm 0.81^{\mathrm{c}}$ \\
WAC (g/g) & $0.98 \pm 0.27^{\mathrm{c}}$ & $1.51 \pm 0.11^{\mathrm{b}}$ & $2.24 \pm 0.26^{\mathrm{a}}$ \\
\hline \multirow{4}{*}{ BET model } & $\mathbf{X m}$ & $0.066^{\mathrm{a}}$ & $0.062^{\mathrm{a}}$ & $0.051^{\mathrm{b}}$ \\
& $\mathbf{C}$ & $46.533^{\mathrm{a}}$ & $29.345^{\mathrm{b}}$ & $19.452^{\mathrm{c}}$ \\
& $\mathbf{R}^{\mathbf{2}}$ & 0.997 & 0.993 & 0.995 \\
& $\mathbf{\% E}$ & 1.089 & 2.798 & 2.456 \\
\hline
\end{tabular}

Values are means \pm standard deviations from triplicate analysis. Different superscript letters in the same file indicated significant difference $(p<0.05)$. LD: lyophilized; CD: dehydrated by convection; ED: extruded; $\mathrm{Xm}$ : moisture of the product corresponding to a saturated monomolecular layer of water; $\mathrm{C}$ : energy constant of the product; $\mathrm{R}^{2}$ : linear correlation coefficient; \%E: relative average error percentage.

\subsection{Physical Characteristics}

The color and texture profile of the obtained powders and rehydrated was influenced by different drying methods (Table 3). The LD was the clearest sample (highest $\mathrm{L}^{*}$ ), while the powders obtained by heating (CD or ED) were darker (less $L^{*}$ ). Hardness of FP was similar to the RP obtained by convection, because the drying was carried out at a low temperature $\left(50{ }^{\circ} \mathrm{C}\right)$, avoiding the formation of hard and dry rind on the surface [4]. The rehydrated LD had less studied textural parameters compared to the other RP and FP; while the rehydrated ED had more determined textural parameters with respect to the FP and the other RP. These results agreed with those informed by Xiao et al. [4] and Wang et al. [3], respectively. 
Table 3. Color and texture profile of the rehydrated powders.

\begin{tabular}{cccccc}
\hline & & FP & LD & CD & ED \\
\hline \multirow{3}{*}{ Color } & $\mathbf{L}^{*}$ & $64.1 \pm 0.4^{\mathrm{b}}$ & $67.4 \pm 0.5^{\mathrm{a}}$ & $62.6 \pm 0.4^{\mathrm{c}}$ & $59.1 \pm 0.3^{\mathrm{d}}$ \\
& $\mathbf{a}^{*}$ & $14.2 \pm 0.4^{\mathrm{c}}$ & $13.1 \pm 0.7^{\mathrm{d}}$ & $15.7 \pm 0.1^{\mathrm{b}}$ & $19.3 \pm 0.9^{\mathrm{a}}$ \\
& $\mathbf{b}^{*}$ & $57.2 \pm 0.4^{\mathrm{c}}$ & $54.8 \pm 0.4^{\mathrm{d}}$ & $61.4 \pm 0.9^{\mathrm{b}}$ & $64.1 \pm 0.4^{\mathrm{a}}$ \\
\hline \multirow{4}{*}{ Texture profile } & Hardness & $11.5 \pm 0.4^{\mathrm{b}}$ & $3.4 \pm 0.1^{\mathrm{c}}$ & $10.7 \pm 0.5^{\mathrm{b}}$ & $34.2 \pm 0.7^{\mathrm{a}}$ \\
& Adhesiveness & $70.4 \pm 2.6^{\mathrm{c}}$ & $16.8 \pm 1.0^{\mathrm{d}}$ & $87.4 \pm 4.7^{\mathrm{b}}$ & $212.2 \pm 2.7^{\mathrm{a}}$ \\
& Cohesiveness & $0.63 \pm 0.01^{\mathrm{d}}$ & $0.69 \pm 0.01^{\mathrm{cd}}$ & $0.80 \pm 0.01^{\mathrm{a}}$ & $0.67 \pm 0.03^{\mathrm{b}}$ \\
& Gumminess & $7.9 \pm 0.3^{\mathrm{b}}$ & $2.37 \pm 0.08^{\mathrm{c}}$ & $8.5 \pm 0.5^{\mathrm{b}}$ & $22.8 \pm 0.4^{\mathrm{a}}$ \\
& Chewiness & $6.9 \pm 0.8^{\mathrm{c}}$ & $2.2 \pm 0.4^{\mathrm{d}}$ & $8.1 \pm 0.7^{\mathrm{b}}$ & $21.3 \pm 0.1^{\mathrm{a}}$ \\
\hline
\end{tabular}

Values are means \pm standard deviations from triplicate analysis. Different superscript letters in the same file indicated significant difference $(p<0.05)$. FP: fresh puree; LD: lyophilized; CD: dehydrated by convection; ED: extruded.

\subsection{Sensory Evaluation and Acceptability}

The FP was described as soft, consistent, clear, mild, pleasant, sweet, fruity, and slightly artificial taste (average acceptability of 7.4 on the hedonic scale). The PD by the different drying methods and reconstituted with water were described as follows: (i) lyophilized-soft, clear, intense flavor, bitter, strange, and unpleasant (3.7 on the hedonic scale); (ii) convection drying-soft, consistent, sandy, clear, consistent, and intense and strange taste (4.4 on the hedonic scale); and (iii) extruded - pleasant, consistent, sandy, dark, mild, fruity, and sweet (6.1 on the hedonic scale).

\section{Discussion}

The apparent decrease in the amount of lipids in the obtained powders was possibly due to the formation of amylose-lipid complexes during the cooking-dehydration processes [3] especially during the extrusion.

The particle size and morphology were different for each drying process, and this influenced the rehydration properties. All the DPs had pores that would facilitate hydration; however, the particles of LD showed homogenous size, which increases the exposure to water and improves the solubility. The particles of $C D$ had contracted and collapsed appearance, which is characteristic when the water diffusion is slow and there is more time for the structures to deform. The ED presented the lowest solubility, probably due to the larger particle size and the agglomeration between them [8].

WAC was higher in this sample, possibly due to the formation of amylose-lipid complexes with water retention capacity and for the breakage of hydrogen bridges which favors hydration capacity [3]. A high WAC is a desirable feature for the preparation of soups, baby food, and instant puddings.

The RP from LP was the clearest, because during the drying by sublimation, non-enzymatic browning reactions are avoided [9]. Non-enzymatic browning reactions and sugar caramelization are promoted during high-temperature drying processes (mainly ED) [10].

The rehydrated of LD had the lowest values of hardness, adhesiveness, gumminess, and chewiness with respect to the other RD and the FP. This result coincides with that reported by [9], who explained that the ice crystals formed during freezing could break the cell structure of the sample and produce softer textures. The rehydrated ED was harder, with more adhesiveness, gumminess, and chewiness than FP and the other RP. This result could be due to the formation of amylose-lipid complexes. Moreover this result could be due to the formation of a hard crust on the particle surface by high temperatures, the rapid evaporation of water, and the high pressure generated between the particles during the process.

The rehydrated purees from $\mathrm{LD}$ and $\mathrm{CD}$ were described with negative sensory attributes (intense, bitter, and strange taste). In addition, the puree reconstituted from LD was described as being more fluid. Consumers differentiated the extruded sample by considering it darker, sweeter, and fruity, with more consistency and harder than the other samples. Therefore, the results of the evaluation of the sensory attributes by CATA method reflected the results obtained through 
instrumental measurements. Valentina et al. (2016) observed that, after lyophilization of some foods, some negative sensory attributes are highlighted with reduction in the acceptability of these products after lyophilization. Jafari et al. [10] observed improvement in the acceptability of bread composed of extruded sorghum-wheat, compared to that made with native sorghum-wheat. These authors explained that extrusion promotes Maillard reactions and caramelization, and therefore a darker and sweeter product is obtained.

\section{Conclusions}

The different drying methods influenced the technological and sensory features of the dehydrated and reconstituted powders.

Consumers were able to differentiate the samples obtained by different drying methods and attributed sensory terms to them that agreed with the instrumental determinations (such as color and texture) made in the samples.

The extruded powder had a better water retention capacity, with appropriate texture and sensory description. Therefore, the dehydrated powder that showed the best characteristics to produce a baby instant puree to reconstitute was obtained by extrusion.

Acknowledgments: This work was supported by grant IaValSe-Food-CYTED (Ref. 119RT0567), Consejo Nacional de Investigaciones Científicas y Técnicas (CONICET) and Secretaría de Ciencia y Técnica y Estudios Regionales (SECTER), Universidad Nacional de Jujuy (Argentina).

\section{References}

1. OMS; Organización mundial de la salud. La Alimentación del Lactante y del niño Pequeño; OPS-OMS: Washington, DC, USA, 2010; ISBN 978-92-75-33094-4.

2. Troszyńska, A.; Szymkiewicz, A.; Wołejszo, A. The effects of germination on the sensory quality and immunoreactive properties of pea (Pisum Sativum L.) and soybean (Glycine max). J. Food Qual. 2007, 30, 1083-1100, doi:10.1111/j.1745-4557.2007.00179.x.

3. Wang, L.; Duan, W.; Zhou, S.; Qian, H.; Zhang, H.; Qi, X. Effects of extrusion conditions on the extrusion responses and the quality of brown rice pasta. Food Chem. 2016, 204, 320-325, doi:10.1016/j.foodchem.2016.02.053.

4. Xiao, M.; Yi, J.; Bi, J.; Zhao, Y.; Peng, J.; Hou, C.; Lyu, J.; Zhou, M. Modification of Cell Wall Polysaccharides during Drying Process Affects Texture Properties of Apple Chips. J. Food Qual. 2018, 4510242, doi:10.1155/2018/4510242.

5. AOAC. Association of Official Analytical Chemists. Methods of Analysis (AOAC). Available online: http://www.aoac.org/ (accessed on March 2019).

6. Wani, I.A.; Sogi, D.S.; Gill, B.S. Physicochemical and functional properties of flours from three Black gram (Phaseolus mungo L.) cultivars. Int. J. Food Sci. Technol. 2013, 48, 771-777, doi:10.1111/ijfs.12025.

7. Tonon, R.; Freitas, S.S.; Hubinger, M.D. Spray drying of açai (Euterpe oleraceaemart.) juice: Effect of inlet air temperature and type of carrier agent. J. Food Process. Preserv. 2011, 35, 691-700, doi:10.1111/j.17454549.2011.00518.x.

8. Ahmed, M.; Sorifa, A.M.; Eun, J.B. Effect of pretreatments and drying temperatures on sweet potato flour. Int. J. Food Sci. Technol. 2010, 45, 726-732, doi:10.1111/j.1365-2621.2010.02191.x.

9. Valentina, V.; Pratiwi, A.R.; Hsiao, P.Y.; Tseng, H.T.; Hsieh, J.F.; Chen, C.C. Sensorial Characterization of Foods Before and After Freeze-drying. Austin Food Sci. 2016, 1, 1027-1031.

10. Jafari, M.; Koocheki, A.; Milani, E. Physicochemical and sensory properties of extruded sorghum-wheat composite bread. J. Food Meas. Charact. 2018, 12, 370-377, doi:10.1007/s11694-017-9649-4. 